\title{
A representação imagética do fato e a verdade evanescente
}

Larissa Soares Carneiro

\section{Resumo:}

Este trabalho discute a natureza do ponto de vista subjetivo, as interpretações individuais recorrentes dele e a construção de um sentido unívoco e ordenado. Parte das reflexões foram levantadas anteriormente por Pier Paolo Pasolini e Manuela Penafria sobre o filme Zapruder, o plano-seqüência fílmico que registrou o assassinato do presidente John Fitzgerald Kennedy. $\mathrm{O}$ artigo acrescenta à discussão o livro ficcional de Ian McEwan - «Reparação» - e as conseqüências da busca pelo sentido a partir da imagem. Para tanto, são abordadas as características inerentes da imagem e seu efeito na psicologia humana e na tessitura da vida social midiatizada. $\mathrm{O}$ artigo argumenta que a construção do sentido jornalístico é fruto das significações e das expectativas que estão no próprio íntimo e consciência daquele que, mediando o fato, narra a acontecimento.

\section{Palavras Chave:}

imagem, sentido, subjetividade, linguagem, significação

\begin{abstract}
:
This work discusses the constitution of the subjective point of view, its individual interpretations and the construction of a univocal and orderly sense. In the Zapruder film, Pier Paolo Pasolini and Manuela Penafria first raised part of these ideas in the plan sequence that registered the assassination of John Fitzgerald Kennedy. The article includes the Ian McEwan book «Atonement» and the consequences of searching for meaning from images. The inherent characteristics of images are addressed for this objective, as well as their effects on human psychology in the formation of mediated social life. The article argues that journalistic construction is the result of the meanings and expectations which lie at the very heart and conscience of every storyteller.
\end{abstract}

\section{Keywords:}

Image, sense, subjectivity, language, meaning

No dia 22 de novembro de 1963, Abraham Zapruder, um ucraniano de origem judaica naturalizado norteamericano, pretendia assistir à passagem do presidente em carro aberto. Por insistência da secretária de sua confecção de roupas femininas, decidiu filmar a visita de John Fitzgerald Kennedy à cidade de Dallas. Seu local de trabalho localizava-se nas imediações da «Dealey Plaza» por onde passaria a caravana presidencial. Zapruder, então, foi à sua residência buscar uma câmera modelo «Bell \& Howell 441 PD Zoomatic Director Series», com lente «Varamat» 9-17mm f1.8 zoom, apta a capturar um plano fechado («close-up») e que utilizava película formato $8 \mathrm{~mm}$ duplo com largura final de $16 \mathrm{~mm}$. A câmera, embora de modelo doméstico, em nada parecia com uma «camcorder video tape» contemporânea, não possuindo, portanto, o dispositivo para a captação de áudio. Às $12 \mathrm{~h} 25$, quando já estava com sua câmera posicionada em um determinado ângulo de onde seria possível assistir/filmar a passagem do presidente, Zapruder fez um «take» de duas de suas funcionários. Uma dela, Marylin Sitzman, acenou para a câmera. Zapruder, então, subiu em uma mureta de concreto e esperou. Assim que a limusine presidencial virou a «Elm Street», às $12 \mathrm{~h} 30$ do horário local, Zapruder começou a executar o que se tornaria o famoso plano sequiência que captou o assassinato de JFK. 
A cena foi registrada pela câmera em uma velocidade de 18,3 quadros por segundos totalizando 486 quadros, ou seja, um espaço de tempo de 26,6 segundos, sendo que a limusine preta do presidente pode ser vista em 343 quadros ou 18,7 segundos. O resultado dessa sugestão acatada por um acaso registrou, também por outro acaso, um dos momentos mais marcantes da história norte-americana que passaria a fazer parte da galeria imagens que representaram diretamente um fato acontecido e é, até hoje, o mais completo filme já rodado de um assassinato. No dia seguinte ao crime, Zapruder vendeu seu filme para a revista «Life» (1) com a condição de que o magazine não exploraria midiaticamente os detalhes capturados pela câmera, devido ao forte clima comoção que atravessava o país. Segundo informações contidas no site do «The Sixth Floor Museum at Dealy Plaza»(2), seis «frames de duas diferentes partes do filme foram danificadas por empregados da revista ao manipularem a película para extraírem fotografias dos fotogramas que seriam veiculadas na revista. De acordo com a mesma fonte, o serviço secreto norte-americano já havia feito uma cópia do filme para fins de investigação criminalística (3), mas o desaparecimento desses seis «frames» deu origem à teoria da conspiração onde o filme original teria sido alterado por órgãos do governo interessados em omitir a verdade (4). Uma verdade que ainda insiste em esvaecer.

O filme Zapruder - como ficou conhecido - já foi visto por milhares de pessoas, foi alvo de inúmeras indagações, montado e re-montado diversas vezes, serviu como evidência material do crime que ele registrou, à construção de diversas teorias de conspirações e outras análises, igualmente fundamentadas, de interesse acadêmico. Uma delas foi concebida pelo cineasta italiano Pier Paolo Pasolini (1922-1975), escrita em 1967 e intitulada «Observações sobre o plano-sequência». Nela, o autor discutiu a construção do sentido a partir do plano seqüência executado por Abraham Zapruder e que fixou em um bem simbólico durável - no caso, a película cinematográfica - o assassinato de JFK. Em outra, Manuela Penafria (2003) escreve sobre o filme ser um paradigma do "cinema direto (5)", a natureza das imagens e a utopia de representar a verdade por meio da representação imagética (6).

\section{O plano-seqüiência e as características da imagem fílmica}

$\mathrm{Na}$ cinematografia, o plano denominado "sequiência" é o mais longo e, cinematograficamente, o mais complexo. Em um mesmo plano é possível realizar diferentes movimentos de câmera: «zooms (7) in e out», «travellings» (8) e/ou panorâmicas (9). Se a história da técnica cinematográfica, como afirma Alexandre Astruc (10), pode ser considerada, em conjunto, "como a história da liberação da câmera (11)", o plano sequiência refuta o antigo «status» da câmera de ser somente um artefato que registra fisicamente um fragmento da realidade circundante, para se configurar como um elemento fundamental da linguagem e da narrativa cinematográfica. A imagem em movimento, então, é um instrumento para imprimir intenções linguageiras e significados.

A história do cinema é prolixa em sua galeria de planos sequiência memoráveis. Tomando como exemplo, poderia ser citada a obra «Filhos da Esperança» (12), do diretor mexicano Alfonso Cuarón, onde a opção intencional por esse recurso de linguagem no filme exigiu que a equipe de filmagem criasse soluções técnicas que permitissem a captação de longas seqüências em locais diversos (13). Porém, talvez o plano seqüência mais discutido e apreciado do cinema de ficção seja o da cena inicial do filme A «Marca da Maldade» (14) de Orson Welles, que possui um meticuloso plano seqüência com a duração de três minutos. Nele, a câmera, fixada em uma grua, segue um veículo em movimento pelas ruas de uma cidade na fronteira entre o território mexicano e norte-americano.

A execução do plano seqüência exige vários movimentos da câmera em uma única cena filmada sem cortes. É um olhar subjetivo. De acordo com Pasolini, há como fazer uma inferência e afirmar que nossas próprias vidas poderiam ser tomadas como um grande plano seqüência ininterrupto feito somente com uma câmera (nossos olhos), nosso ponto de vista privilegiado (o sujeito-protagonista) e um gravador de áudio (nossos 
ouvidos).

A imagem captada artificialmente do assassinato de Kennedy configura, então, um plano seqüência de natureza documental obtido por meio de uma só câmera, isto é, de um só olhar. Entretanto, ao espectador que assiste ao filme, a cena que desenrola à sua frente é inconclusa. Existe um crime, mas não sua causa ou o seu efeito. Mostra em detalhes gráficos a cabeça do presidente sendo atingida por um tiro, mas é impossível verificar o momento e o local de onde o tiro foi disparado. Sequer é possível ouvir o som do disparo. Não se sabe como e por que aquilo aconteceu. Faltam para a compreensão do fato - conclui Pasolini - outros pontos de tomada: o do assassino (ou assassinos), da primeira-dama Jackeline Kennedy, que estava ao lado; o «travelling» lateral que captaria a reação do público que assistia à passagem da comitiva presidencial; o plano inteiro que registraria o corpo do presidente e o interior do veículo; alguns «closes e «takes» de detalhe; enfim, os outros diversos pontos de vistas de uma mesma história, os seus milhares de enquadramentos possíveis, que completariam a história feita por uma série de imagens subjetivas.

A imagem é a matéria-prima da narrativa audiovisual e é, em si, uma forma de discurso bastante complexo.

Sua gênese é com efeito marcada por uma ambivalência profunda, pois é produto da atividade automática de um aparelho científico capaz de reproduzir exatamente a realidade que lhe é apresentada, desde que esta atividade seja dirigida esteticamente no sentido querido pelo realizador (MARTIN, 1963: 17).

Sobre a imagem repousa um determinado número de características que precisam ser explicitadas para que se tenha a medida exata de sua importância na psicologia humana e na tessitura da vida social midiatizada. Uma das principais características da imagem fílmica é que ela é dotada de muitas aparências de realidade, já que o realismo enquanto uma concepção estética é um efeito, uma interpretação, uma transfiguração da realidade. Outro caráter importante da imagem cinematográfica é que ela sempre está no presente. Assim funciona a nossa percepção e nossa consciência frente à imagem em movimento. “(...) O desnível temporal somente se dá pela intervenção do julgamento, único capaz de dispor os acontecimentos diegéticos como passados em relação a nós ou determinados planos temporais na ação do filme" (MARTIN, 1963). Mas a imagem constitui-se em uma "realidade artística". É uma visão escolhida, estética, composta da representação da natureza. Não é somente uma cópia, um espelho indefectível da realidade circundante. No caso específico do filme de caráter documental, o fato realmente, de alguma maneira, aconteceu, mas, como afirma Manuela Penafria (2003), a tentativa de registrar a realidade em sua totalidade se revela como uma utopia do planosequência que menospreza os outros pontos de tomada possíveis e imagináveis.

Uma outra característica da imagem é que ela tem um caráter absolutamente significante. Pode não o ser de uma maneira direta e unívoca, mas opera por meio do sistema cognitivo simbólico de cada um que com ela toma contato. Sendo assim, a imagem final que será percebida é fruto da intenção de seu autor e da predisposição cultural e humana de quem a vê e lhe imprime significações particulares.

Quanto ao indivíduo, a esse não é dada a faculdade de ver - ou imprimir a imagem - senão de um único ângulo visual no qual ele se encontra. Uma câmera, portanto, capta o que viu um determinado sujeito em uma determinada relação tempo-espaço. Kant em sua «Crítica da Razão Pura» define o fato como algo inserido impreterivelmente na relação tempo e espaço. Sem essa dualidade, o fato não existe. A imagem captada em movimento cristaliza, então, um ínfimo fragmento espacial do mundo inserido dentro de uma determinada e fugaz duração de tempo que denominamos "fato". Um tempo sempre presentificado e o plano sequiência que acompanha, como nossos próprios olhos, o desenrolar do acontecimento é a quintessência deste fato, desse extrato da realidade levado ao máximo de apuramento. A imagem sugere a idéia de que algo está acontecendo (transmissão "ao vivo" pela televisão) ou aconteceu independente da câmera que o capta. A câmera estaria somente posicionada naquele lugar e o fato independeria dela, como o próprio assassinato do presidente, 
filmado por um acaso.

\section{A construção do sentido e as outras possibilidades de enquadrar um fato}

E então Pasolini se pergunta: se aquelas outras filmagens tivessem sido feitas, o que teríamos em mãos? O diretor nos convida a um «faz-de-conta» e nos pede para imaginar - ou seja, produzir imagens - que haveria naquele momento uma série de outras câmeras posicionadas, outros planos sequiência frutos diretos e objetivos de outros tantos pontos de tomada, para usar a nomenclatura cinematográfica. Uma série de planos sequiência que reproduziriam as coisas e as ações reais do momento da ação por meio de uma série de subjetivas que são, para ele, o limite realista máximo da técnica audiovisual que é, a priori, realista. Para ele, o resultado dessa empreitada seria o de uma "multiplicação de 'presentes' como se uma ação, ao invés de ser desenrolar uma única vez diante de nossos olhos, se desenrolasse várias vezes" (1981: falta página). Para Pasolini, o efeito imediato dessa multiplicação de presentes seria, na realidade, a abolição do presente, esvaziando-o, colocando-o sob perspectivas, relativizando-o diante de outros tantos pontos de vista, revelando, assim, a sua ambigüidade, a ausência do unívoco e a incerteza de que aquilo precisamente aconteceu.

Em sua obra literária «Reparação», Ian McEwan aventa, «lato sensu», a possibilidade que a arte teria de reparar a vida vivida, mas, «strictu sensu», discorre sobre o fato de nossas vidas não serem nada mais que um grande plano sequiência onde tentamos desesperadamente reparar e corrigir a nossa ação imediata anterior que, inserida em um «continuum» temporal irreversível, não nos permite a confecção de um segundo «take »melhor e mais apropriado para o alcance da felicidade e da realização da vida. No livro, há uma cena particularmente paradigmática (15) e significativa sobre a existência de outros pontos de vista, além do próprio, que relativizam a percepção realidade - como defende Pasolini - e a certeza de que, aquilo que vimos e interpretamos por meio de nosso sistema simbólico e cognitivo, realmente aconteceu. O ano é o de 1935 e a Inglaterra vive uma intensa onda de calor. O dia é o mais quente de muitos outros dias já vividos. A menina Briony, de 13 anos, escritora compulsiva de historietas fabulares com ensinamentos morais onde, ao final, tudo termina bem, vê da janela de seu quarto uma cena que ela registra somente com seus olhos. Nela, sua irmã mais velha, Cecília, está junto à fonte do jardim. Tem em suas mãos um vaso e em sua companhia está Robbie, filho da faxineira da casa que pertence à sua família. Imediatamente, em um processo mental associativo, a cena desperta em Briony a recordação de uma de suas histórias, onde um humilde lenhador salva uma princesa e termina por se casar com ela. Divagando, Briony imagina que talvez Robbie esteja propondo casamento à sua irmã. Isso fazia sentido para ela. Robbie, um rapaz ousado que tinha os estudos custeados pelo pai da menina, seria bem capaz disso. Porém, o gesto subseqüente de Robbie não se enquadra em sua narrativa imaginada. Antes sentado na mureta da fonte, junto à sua irmã, ele se levanta depressa e então, inexplicavelmente, Cecília começa a se despir. Briony não entende o que vê. Imagina que essa ação peculiar e não convencional foi ordenada pelo rapaz e atribui a Robbie um estranho poder maléfico de autoridade. Sente vergonha por sua irmã; por seu papel desempenhado; por sua inferioridade; submissão; por sua fraqueza. A irmã, somente com suas roupas íntimas, entra então no laguinho e mergulha desaparecendo de seu campo de visão. A ação congela por um momento. Nada se move. Nada acontece. O plano seqüência do ponto de vista de Briony não tem uma lógica. Após o quase afogamento no laguinho, afinal, deveria haver uma cena de resgate por parte do rapaz e então, finalmente, o pedido de casamento. Essa foi a última coisa que Briony pensou antes de aceitar o fato que não conseguia compreender o que via. Nesta cena, a ela só cabia assistir. Sendo assim, o controle da cena, do desenrolar dos fatos, a ordem, escapava das mãos da menina-autora que construía, por meio de sua arte, destinos e os alterava a seu bel-prazer. Ali, naquele momento, deu-se conta que era tão só uma espectadora de ritos adultos, os quais ela ainda não conseguia compreender. Ao ver surgir a cabeça da irmã no lago, percebe que deste momento em diante nunca mais escreveria contos de fada e sim a estranheza desse «aqui e agora»; aquilo que se passava no íntimo de cada um; com as pessoas que ela conhecia; o poder que se exercia sobre o outro e de que como era fácil entender 
tudo errado.

Briony percebeu - de maneira similar à conclusão de Pasolini e Penafria - que a verdade não se constitui de somente um ponto de tomada; ela pertence a cada um, a nenhum e a vários pontos de vistas diversos. É impossível compreender a narrativa, pois essa nunca é encenada somente «para»e «por» você. Aquilo que ela, afinal, tinha visto não era um conto de fadas, mas a "realidade". Sentiu um ímpeto de exigir explicações e poderia ter feito, mas gostaria, por outro lado, de perpetuar a sensação de que a cena, por fim, adquiriria o seu sentido com o decorrer dos anos. Com a passagem do tempo. Com o acréscimo natural de outras narrativas à cena que ela própria haveria de captar. Deu-se conta que poderia escrever o que já havia visto e que poderia incluir nela um outro observador oculto. Melhor, poderia escrever a mesma cena sob três pontos de vistas diversos: o seu, o de sua irmã e o de Robbie. Uma história que não seria marcada pela presença do bem ou do mal, por julgamentos morais, por sentidos fabulares, porque ninguém é absolutamente mal ou bom. Disso, ali, de sua janela, naquele momento fugaz, ela havia se dado conta. Mas se não era preciso julgar, era preciso conferir, à cena, um sentido. Havia apreendido que existem outras pessoas que eram tão reais quanto ela própria e isso merecia ser gravado em um papel. Neste momento ela atravessou,

com seus escritos, toda a história da literatura, começando com as histórias baseadas nas tradições folclóricas européias, passando pelo drama com intenção moral simples, até chegar a um realismo psicológico imparcial que descobrira sozinha, numa manhã específica, durante uma onda de calor em 1935 (MCEWAN, 2002: 55).

Foi ao se dar conta da existência de outros pontos de vista que Briony deixou de ser criança. Perceber as outras possibilidades de enquadrar um fato significa, para Ian McEwan, o processo de maturidade emocional.

\section{A intervenção na realidade: da subjetividade à objetividade}

Voltemos agora ao filme de Kennedy e às indagações de outro artista, Pier Paolo Pasolini. Se mais de um ponto de tomada - ou par de olhos - houvesse, qual desses filmes representaria, com maior aproximação, a realidade dos fatos? Para o autor, isolada, cada cena não consegue dar conta da realidade e da construção de um sentido; é pobre, visto que é apenas um só ponto de vista em um universo múltiplo de possíveis outros. Como a cena vista da janela por Briony, o filme de Zapruder trata-se de um plano único que resulta em um vazio provocado pela ausência da representação de outros pontos de vista sobre o mesmo acontecimento. Em todos eles, seria possível dizer que a realidade, de algum modo, se expressou; que disse algo a quem estava presente, "porque a realidade não fala com outras coisas senão consigo própria" (referência). Manifesta-se e diz alguma coisa com a sua linguagem que é linguagem da ação. O carro passando, a cabeça do homem sendo lançada para trás, sua queda para frente, a mulher que se arrasta para a traseira do veículo são signos não simbólicos - não convencionados - que dizem que ali aconteceu alguma coisa. Mas o quê? E é aí que se dá a busca por um sentido que seja unívoco; de uma sistematização relativa ao indivíduo e ao mundo objetivo; uma busca de relação entre todas as narrativas presentes, os diversos pontos de vista e de tomada. É quando se torna imperativa a busca pelo ordenamento. Enquanto todos eles - esses "sintagmas vivos", como define Pasolini (referência) - não forem colocados em uma relação entre si, eles não farão sentido algum. Para isso, é preciso interferir na realidade. Construir e impor um significado ao mundo (PENAFRIA, 2003).

O que deverá, então, acontecer para que essa avalanche de imagens se torne completa, lógica, racional e compreensível? É preciso haver uma ordenação desses planos. Proceder com a narrativa. Para Pasolini, por meio dela, tornar, enfim, o presente passado. "Somente os fatos acontecidos e acabados são coordenáveis entre si e, portanto, adquirem sentido" (1981: 195). É como a alegoria da história representada pelo vôo noturno da coruja sugerido por Maurice Merleau Ponty (16). Aquela somente poderia ser compreendida já no seu crepúsculo, quando estivesse terminada. Quando a história fosse fato passado e analisado sob um ponto de vista elevado, acima de todos, onde seria possível ordenar todos os outros pontos de vista. Haveria que se 
escolher, então, dentre todas as tomadas, aqueles que são os melhores momentos; as cenas verdadeiramente significativas dos vários planos seqüência subjetivos e descobrir, para sua eventual montagem, a sua ordem natural. A subjetividade daria, assim, lugar para a objetividade. Desapareceria a subjetividade daquele que registrou a cena e daí emergiria o sentido finalmente construído do fato, com sua causalidade e consequiência inerente. Já não haveria mais série randômica de visões incompreensíveis e ambíguas - como a cena vista por Briony de sua janela - mas a presença de um narrador, que como um deus, ordenaria o sentido. Um narrador que transformaria o presente incompreensível e caótico em um passado contado e ordenado. Que afirmaria: "foi exatamente isso que aconteceu". E as características intrínsecas da qualidade da imagem e do meio audiovisual representariam um extrato da realidade para sempre presentificado - um presente histórico.

Pasolini argumenta que a realidade tem sua própria linguagem que precisa de uma semiologia própria que, entretanto, nos falta. Uma linguagem que se refira ao homem que se expressa por meio de suas ações, já que são elas que modificam o espaço e as suas relações. Uma ação que é destituída de sentido enquanto não for concluída. E por isso, o autor conclui: "é assim absolutamente necessário morrer, porque enquanto estamos vivos, falta-nos sentido" (1981: 196). A linguagem da vida enquanto vivida é intraduzível. Um caos de possibilidades, de desvios ilógicos, de acasos, de tragédias, de acidentes de percurso, de mal entendidos. "A morte realiza uma montagem fulminante da nossa vida" (1981: 196).

Finda a experiência, são escolhidas as melhores cenas, as mais significativas, outras são inventadas, intencionalmente ou não, e desse ajuntamento de pedaços desconexos se constrói um sentido que, talvez, não tenha a chance de ser reparado no futuro. Essa montagem reproduz um passado que é coerente, estável, certo e, sobretudo, desejável. Um passado descritível, mensurável, controlado e concreto porque foi mediado. Penafria argumenta que assim se baseia, também, a lógica jornalística. Para ela, o jornalista assume o papel de narrador - de mediador - entre a realidade por ele captada - por seu ponto de vista acrescido de alguns outros (fontes e testemunhas) - e os coloca linear e sequiencialmente na promessa de cumprir o imperativo da objetividade do fato. Ao espectador, cabe acreditar que aquilo que ele vê representado na imagem realmente, de alguma maneira, aconteceu.

Como não podemos estar em todo o lado ao mesmo tempo, precisamos que as imagens que chegam até nós sejam verdadeiras, para podermos gerir a nossa relação com o mundo. (...) Este é o papel que reservamos para os jornalistas: que nos mostrem os acontecimentos do melhor ponto de vista, uma vez que também eles, não podem ver os acontecimentos de todos os ângulos (...) (2003: 9).

No livro de McEwan, a velha Briony passa a sua vida - que já se esvai em um processo significativo de perda gradativa de memória (afinal, o que é o indivíduo sem o seu depositário privado de imagens significadas?) buscando reparar as trágicas conseqüências da mal compreendida cena captada por seus olhos da janela de sua infância. Desse único ponto de vista que, por ela imaginar ser de algum modo privilegiado, seria o mais verdadeiro. No decorrer dos próximos sessenta anos, acumula outras narrativas, outros pontos de vista sobre a mesma cena passada, para conferir às vidas perdidas, um sentido. Lamenta e almeja reparar o inconseqüente ato de ter divulgado um só ponto de vista. Como narradora, seleciona os momentos mais significativos das diversas narrativas, procede a montagem e interfere no final de sua história.

\section{A significação dos fenômenos}

Esse fenômeno não é estranho à psicologia humana. Em meados do século 19, alguns pesquisadores alemães, dentre eles Kurt Koffka, Wolfgang Köhler e Max Werteimer, principiaram a estudar os fenômenos que envolviam a percepção humana advinda principalmente da visão. Mais tarde, esses estudos foram denominados de psicologia «Gestalt» (17) ou da Boa Forma. De acordo com a teoria, não é possível conhecer o todo a partir de suas partes isoladas e o indivíduo, ao se deparar somente com um dos fragmentos do objeto, possui a tendência à restauração daquele objeto fragmentado. $\mathrm{O}$ aparelho psíquico, neurologicamente, procura 
o equilíbrio da forma - a ordem - garantindo o entendimento do estímulo visual que lhe é dado. Haveria, então, a busca pelo fechamento do sentido, pela simetria confortável e pela regularidade da experiência. Essa tendência em juntar os elementos esparsos para a sua apreensão denomina-se «força do campo psicológico». Isso quer dizer que somente é percebido aquilo que encontra as pré-condições para o sê-lo. Pois Briony, para "fechar a «gestalt»" - produzir o sentido final - acrescenta e altera elementos à sua narrativa. Constitui o seu presente histórico. Opta por uma versão menos impiedosa para com os personagens, mas principalmente por uma versão menos impiedosa de si mesma. Afinal, o sujeito é e percebe somente a partir de seus hábitos, de sua cultura de suas predisposições. Como justificativa desse seu ato de ética discutível, a narradora pergunta ao seu público-receptor como uma história poderia não terminar bem. "Que sentido, que esperança, que satisfação o leitor poderia extrair de um final como esse (...) Quem iria acreditar nisso [em um final terrível], a menos que fosse em nome do realismo mais árido? (...) Ninguém está interessado em saber quais os eventos e quais os indivíduos que foram distorcidos no interesse da narrativa. Sei que haverá sempre um tipo de leitor que se sente obrigado a perguntar: mas, afinal, o que foi que aconteceu «de verdade»? (MCEWAN, 2002)"

Ao curso natural da vida cotidiana falta-lhe ordem e essa última é uma criação humana. Ela contrapõe a idéia do caos que desestabiliza, foge ao controle, à "visão plena, mesmo que geralmente ilusória" (MARCONDES FILHO, 2002: 223).

Pois no interesse de contar uma história que soe como verídica e de representá-la para os receptores, o sujeito transfere para o fenômeno as significações e as expectativas que, em geral, estão em seu próprio íntimo e consciência. Seja uma tendência consciente ou não, cultural ou instintiva, a busca pelo sentido - da ordem -, da compreensão dos fatos mais complexos e prosaicos da vida cotidiana se torna um imperativo. Ao não "fechar a «gestalt»" (18), a psique humana se ressente e demanda pelo desejo de reparação. Sendo assim, permanece uma outra indagação: em que medida os profissionais da mídia que narram o mundo, não realizam as suas próprias alterações; acrescentando, por vezes sem perceber, cenas que imaginam ou gostariam de ter visto; julgando segundo os seus próprios critérios para que possam poupar não só as vítimas, mas também a si mesmos, do julgamento do mundo?

\section{Bibliografia:}

MCEWAN, Ian. Reparação. São Paulo: Companhia das Letras, 2002.

MARCONDES FILHO, Ciro. O espelho e a máscara: o enigma da comunicação no caminho do meio. São Paulo: Discurso, 2002.

MARTIN, Marcel. A linguagem cinematográfica. Belo Horizonte: Itatiaia, 1963.

PASOLINI, Pier Paolo. Observações sobre o plano-sequência. In: Empirismo herege. Lisboa: Assírio e Alvim, 1981.

PENAFRIA, Manuela. O plano-sequência é a utopia. O paradigma do filme-Zapruder in MIDIA BR, Livro da XII Compós. Org. André Lemos et al. São Paulo: Meridional, 2004, p 207-222.

REISZ, Karel \& MILLAR, Gavin. A técnica da montagem cinematográfica. Rio de Janeiro: Civilização Brasileira, 1978.

\section{Notas:}

(1) Do grupo Time-Life de comunicação.

(2) The Sixth Floor Museum at Dealy Plaza é um museu de cunho educacional e histórico dedicado a "examinar a vida, a época, a morte e o legado do presidente John F. Kennedy dentro do contexto da história norte-americana". Disponível em: http://www.jfk.org/home.htm. 
(3) A cópia do filme original - com os seis frames - encontra-se no Arquivo Nacional.

(4) O roteiro do filme do cineasta Oliver Stone - JFK - sustenta-se sobre essa teoria da conspiração.

(5) Segundo Penafria, o cinema direto "foi um dos movimentos que se apoiaram na utilização de equipamento leve e de som síncrono. Mediante o uso de tais dispositivos, o cinema, particularmente o documental, buscaria por meio de determinadas convenções dar ao espectador um "acesso direto e linear ao nosso mundo".

(6) O plano-sequência é a utopia. O paradigma do filme-Zapruder (in LEMOS, 2004).

(7) Recurso de aumentar uma parte escolhida da imagem pelo emprego de uma lente especial dando a impressão de ora aproximar e ora se afastar do assunto.

(8) "Movimento de câmera sobre carrinho de rodas ou trilho, paralelamente ao assunto que está sendo filmado" (REISZ \& MILLER, 1978).

(9) Ação de girar a câmera sobre um eixo - fixo ou não - num plano horizontal durante a filmagem.

(10) Alexandre Astruc é cineasta e crítico francês, nascido em 1923. A citação deste artigo foi publicada no periódico L'Ecran français, n. 101, 03 de junho de 1947 e citada por Marcel Martin em seu livro A linguagem cinematográfica, ed. 1963.

(11) Georges Sadoul esboça em seus trabalhos a história da liberação da câmera, já que durante muito tempo a câmera mantinha-se fixa em sua imobilidade.

(12) Children of Men (EUA, 2006). Direção e roteiro de Alfonso Cuarón. Duração de 109 minutos.

(13) Uma delas, de difícil execução, foi realizada no interior de um veículo em movimento com a presença de quatro atores.

(14) Touch of Evil (EUA, 1958). Direção de Orson Welles.

(15) Reparação, ed. 2002, p 52-56.

(16) Filósofo fenomenologista francês (1908-1961).

(17) A palavra alemã Gestalt é de difícil tradução para o idioma português. O mais próximo seria "forma" ou "configuração".

(18) Na teoria da Gestalt, o termo significa o movimento de restaurar a harmonia do todo; restaurar o que está errado.

\section{Mini Currículo :}

Graduada em Comunicação Social - habilitação jornalismo - e mestranda do Programa de Pós-Gradução em Comunicação Social - Interações Midiáticas da PUC-Minas. E-mail: larissagrau@ @mail.com. 